needle is sure to prove effectual only when a precise diagnosis can be made of the place and of the depth of the injury. These can be ascertained only by specialists who are in the daily habit of using the urethroscope.

The method of treatment in prostatic hypertrophy by means of electricity has been studied in several ways and with variable results. Tripier, Minervini, Mallez, and Vautrin have applied the faradic and constant current of an energy of 30 to 100 milliampères, but with slight success.

Electrolysis, or electropuncture, was first applied in France, at a later period in Germany also by Biedert and Casper, and in Switzerland by Roux. Casper operated on the lateral lobes; he determined with the finger the site of the posterior wall of the prostate, and with the other hand he forced in the glass-protected needle charged from the negative pole. The current lasted five minutes, and was applied in different places ; the energy of the current was from 10 to 25 milliampères; the number of sittings was twenty and higher. Though the results were not very favourable, and though once a vesico-rectal fistula supervened, Casper nevertheless recommends the electrolytic treatment, so that further experience may be gained He used a platino-iridium needle, Biedert a curved platinum needle, and Roux a steel one.

The electrolytic method of treatment does not as yet rank among the recognized and lasting treatments of prostatic hypertrophy, on account of the incidental complications-abscesses, fistulas - and also owing to uncertain results. May I again call my colleagues' attention to this method, which assuredly has a great future before it?

\section{INTRACRANIAL HAEMORRHAGE IN THE NEWBORN.}

\section{By J. CAMERON TURNBULL, M.D.GLAs.,} BURY, IANCASHIRE.

As a commentary on your article on the above subject in a recent number, ${ }^{1}$ may I be permitted to give the following notes of a case which occurred about eighteen months ago:

I was called one night by a midwife to attend a multipara. She had been in labour for three days, and during the previous day had had severe pains without making much progress. When I saw her she was in a state of nervous prostration and her pulse was rapid. The pains were almost continuous, their character suggesting uterine fatigue. On vaginal examination, the os was found fully dilated, and the head engaging in left oblique, occiput anterior. The pelvis was capacious and there was no deformity. Forceps were introduced, and grasped the head over the left frontal and right occipital regions. Very moderate traction was required to bring the head past the brim, and the instruments were reintroduced in the transverse diameter, delivery being completed easily. The child was well developed, and not asphyxiated to any great extent. Within a few minutes it was crying lustily. During the first day it appeared perfectly well except for a slight ecchymosis over the left eyebrow. About twentyfour hours after birth the mother noticed that it had a strange cry, and a short time afterwards I was sent for to see it in convulsions. These vere tonic in character and affected the whole body; and, except that the right arm was thrown about more than the left, they were equal on both sides. The pupils were equal and moderately contracted, and there was no squint. The respirations were jerky and stridulous, and at times would cease, the face becoming suffused with a deep flush. Deglutition was very imperfect. The application of ice to the head seemed to quieten the child, but on the slightest movement or sound in the room the fits would recommence as severely as before. The child gradually became comatcse, and died forty-five hours after birth.

With the assistance of my friend, Dr. J. Dunlop Lickley, the head was opened, and the following condition of affairs revealed. There was no fracture, and no extradural haemorrhage. The brain matter was soft and pulpy and the pial vessels congested. The whole base of the skull on both sides, but chiefly on the left, was filled with dark fluid blood and blood clot, up to the level of the Sylvian fissure, the upper aspect of the hemispheres being clear.
On the left side it extended over the temporo-sphenoidal lobe, into the lips of the Sylvian fissure, and backwards on to the occipital lobe. On both sides it was found between the occipital lobes and cerebellum, and on the orbital surfaces of the frontal lobes. On removal of the brain, all the subarachnoid spaces were found filled with bloodstained fluid. The main arteries and venous sinuses were followed out but no trace of rupture or disease was discovered. None of the fissures contained any effused blood, the Sylvian fissures being notably clear except for the small amount previously mentioned as extending between the lips on the left side. No ante-mortem clot was found anywhere. Section of the brain substance showed it to be markedly congested and oedematous, but free from extravasation. The lateral ventricles were considerably distended with clear fluid and the choroid plexuses were engorged.

The appearances, therefore, seemed to indicate a haemorrhage into the subdural space, probably from rupture of one or more vessels in the pia covering the lower aspect of the left hemisphere. The pressure of the effused blond on the veins of Galen and cranial sinuses had given rise to oedema of the brain and internal hydrocephalus.

The inferences which I draw from this case are: (1) That the haemorrhage cannot wholly be accounted for by direct injury to the head from either forceps or pelvic bones. To my mind, the high cerebral blood pressure which must result from rigid contraction of the uterus on the placenta and soft parts is a much more important factor, and indicates delivery before the uterus is fatigued, as a prophylactic measure. (2) That it would be extremely difficult to locate and ligature a ruptured vessel if craniotomy were performed, as Cushing suggests.

1 British Medical Journat., February 10th, 1906, p. 342.

ASCARIS LUMBRICOIDES AND APPENDICITIS. BY F. E. ANLEY, M.R.C.S., L.R.C.P.,

\section{SURGEON, R.N.}

Tut following remarks concern a possibility which I have never yet seen discussed, and may prove of some interest to medical men, especially those serving in foreign countries, where the above nematode is more commonly met with than in Europe. China may be looked upon as the particular happy hunting grounds of the Ascaris lumbricoides. In some parts of the country it is so common that many people go through a regular course of santonin every year in the spring, and it is often hearcl said of the Chinese that they are not healthy without one of these inhabitants of the intestines. While serving in H.S. Leriathan on the China station I found how common the ascaris was, but it was not until I was lent to the Royal Navy sick quarters at Wei-hai-Wei that the idea of connecting them with the above disease occurred to me. The following are cases in point:

Lieutenant $\mathrm{X}$, H.M.S. Leviathan, while bringing a destroyer up from Hong Kong, was suddenly seized witl what appears to have been a typical attack of appendicitis (catarrhal). The attack began with vomiting, accompanied by pain, tenderness, and rigidity in the right iliac region, constipation; temperature, $100.8^{\circ}$; pulse, 100 ; tongue furred, etc. When admitted to Wei-hai-Wei sick quarters he was beginning to improve, the abdominal symptom: were still present, and a tumour could be felt in the region of the appendix ; temperature, $99.4^{\circ}$. He passed a typical convalescence, and returned to duty. A few days later he passed a round worm.

The second case is that of Midshipman Z, H.M.S Centurion; the history of his case is very similar: catarrhal appendicitis with nausea, vomiting, pain, tenderness and tumour; temperature, $102^{\circ}$. As the patient did not improve on treatment in hospital it was decided one evening to operate on the following morning, examination of the blood having shown leucocytosis to be present. In the morning, however, he passed a small motion containing a round worm, and from that time made an uninterrupted recovery.

On speaking to Fleet Surgeon Vidal Thorpe I learned that he had had 2 similar cases in Wei-hai-Wei sick quarters one of which was operated upon and the appendix 
removed; during convalescence the patient passed a round worm.

The habit of the ascaris of inserting itself into apertures and ring-like bodies is well known, and it has seemed to me that an inflammation may be set up by the worm attempting to enter the appendix, sufficient to cause blocking of the lumen, leading to a resultant catarrhal appendicitis; or the worm may actually obtain a partial entrance if not more.

\section{ME MORA NDA: MEDICAL, SURGICAL, OBSTETRICAL.}

MEASLES COMPLICATING ENTERIC FEVER. In the British Medical Journal of February 10th Dr. Malcolm Campbell called attention to some interesting details in three cases of measles, in one of which pregnancy and the puerperium seemed to delay and modify the attack. In connexion with this subject the following case is of interest, the patient contracting measles during convalescence from enteric fever. He was visited by a relative who was in the prodromal stage of measles, and who subsequently had a severe attack, with well-marked bronchitis, the temperature not falling to normal for ten days. About a fortnight after this my patient developed measles and had a pronounced rash, but the whole attack was over in four days. The most interesting feature of the attack was the complete absence of catarrhal symptoms, or, indeed, of symptoms of any kind, for the patient never felt ill. There was no sputum, no cough, and no bronchitis; not even

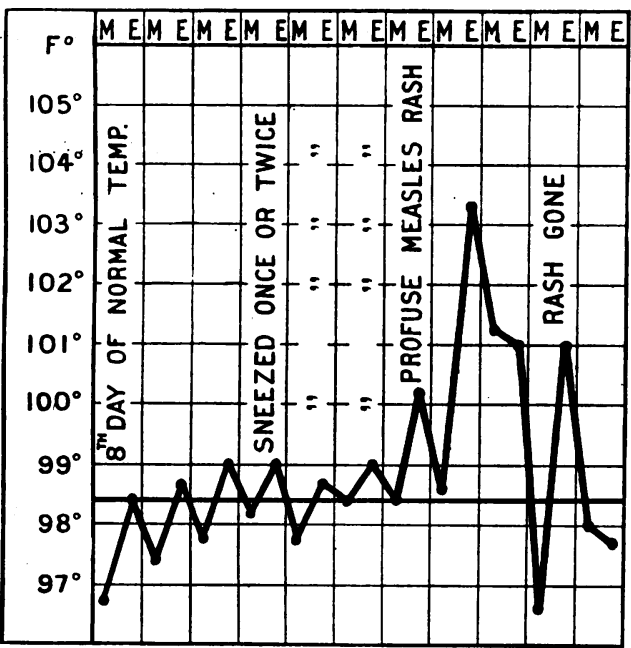

sore throat or nasal catarrh. Since both measles and enteric fever are often associated with or followed by pulmonary complications, it was natural to watch the lungs with special apprehension, yet they remained singularly free throughout. Neither of these patients had previously suffered from measles. The whole course of the attack in the enteric fever patient makes one wonder whether or no there is any natural antagonism between the virus of enteric fever and that of measles. On the other hand, the mildness of the attack of measles might have been due to the freedom from exposure during the prodromal period. This would apply equally to the parturient lady mentioned by Dr. Campbell. I should add that in both of my cases the incubation period could be fairly accurately measured. In the first it was exactly fourteen complete days; in the enteric fever patient it was fourteen, fifteen, or sixteen days.

San Remo, Italy. Cecil F. Lillie, M.A., M.D.Cantab.

LUMBAR PUNCTURE IN PUERPERAL ECLAMPSIA. IN considering the pathology of infantile convulsions and the recent treatment of lumbar puncture in these cases, I was led to speculating on its value in the analogous condition of some parturient adults. Eclampsia usually arises in cases with marked symptoms of disturbance of the kidneys, but whether the convulsions are due to toxaemia or to pressure on the cerebral centres has not been finally settled by pathologists. I shortly had an opportunity of trying the treatment in two cases, with results so gratifying that $I$ think my experience may be of value.

CASE I.-On Sunday, June 5th, 1904, I was called to Mrs. M a primipara, at 4.30 p.m. The labour was normal, and terminated at 7.30 p.m. At midnight I was called again and informed that the patient had had a fit; whilst $I$ was in the room she went into an eclamptic convulsion. I gave a whiff of chloroform, and the convulsion stopped, the patient regaining consciousness in a few minutes. From then onward until the following afternoon she bad fits at about two hours' interval, remining consciousness between ; from $4 \mathrm{p}$ m to $7 \mathrm{p}$.m. she had fourt with deep un; from 4 p. with deep unconscious salt solution, croton oil, and wet packs. At 7 p.m. her pulse was irregular, quick, and feeble; in fact, she was rapidly dying. I then punctured in the third lumbar interspace with the needle of $\mathrm{my}$ antitoxin syringe and obtained a rapid dropping of fluid for some minutes. The fits ceased, and the patient gradually resumed consciousness, so that at midnight she was rouseable and the pulse distinctly better. At 3 a she had a slight fit, but otherwise a quiet night, and was quite conscious in the morning. Thence onward the progress was uneventful.

CASE II.-On February 12th, 1905, I saw, at 10 a.m., in consultation, Mrs. B., a primipara, who had been having fits frcm 6 o'clock the previous evening. She was in a convulsion as we entered the room. The head of the child was on the perineum, and $I$ at once delivered with forceps, whilst my collesgue controlled the convulsions with chloroform. Afterwards the patient remained deply unconsous, with stertor and blue face; the pulse was iregur I returned bout face; the pulse was irregular and quick there had been no return of consciousness. The pulse was scarcely perceptible, and the breathing was bad, only about one respiration in three getting any air into the chest, showing the respiratory centre giving way, either from poison or pressure. Pilocarpin hot pack, croton oil, and other remedies had been tried, and I now introduced a needle into the third lumbar interspace I used a needle from my aspirator of larger calibre than on the previou un when the patient became unruly and I had to withdraw the needle; her breathing was now regular and her eyes opened intelligently. She had no more fits, and gradually recovered consciousness during the day and made a normal convalescence.

Since these cases I have had two others of a milder form, both recovering on emptying the uterus without resorting to other measures.

Maryport.

F. Proud, M.D.Durh.

\section{HIGH-FREQUENCY CURRENT IN ERYTHEMA} PAPULATUM.

Mrs. S., aged 23, was first seen in May, 1904. She gave a history of an attack of rheumatic fever two years previously, and since then she has suffered from rheumatism more or less. The larger joints were principally involved. Shortly after the first attack she observed an eruption on her face and arms, which has remained more or less constant ever since.

When she first came under observation she complained of pain mostly in the ankles and knees, which were slightly swollen. She was anaemic, and her general health poor. The heart and lungs were normal. The condition of the skin was as follows: There was an eruption on the back of both forearms, on the back of both shoulders, on the nape of the neck, and on the face, principally on the forehead and round the eyes, with a few isolated spots on the cheeks and nose. This eruption consisted of papules varying in size from a millet seed to the size of a wooden match-head. The smaller ones were of a red hue, which paled on pressure. The larger ones were firm and elastic to touch, and were of a deeper red, passing on to a blue colour. Some of them assumed a cyanotic appearance. All the papules were elevated above the general cutaneous surface, and crowded together without any order. In some of the larger ones vesicles formed in the centre, which broke and dried up. In this case the papule tended to pass through bruise-like changes, and in the event of its subsiding altogether, as some did, small pit of a bluish colour showed where it existed.

Drug treatment was employed in the first instance. Internally, salicylate of soda, iodide of potash, iron, arsenic, and sulphide of calcium were given from time to time. Locally, sulphur lotion, lead lotion, ung. hydrarg. nit., and ung. ichthyol. were applied. The rheumatism and the general condition of the patient improved somewhat, but the skin condition made no progress whatever, 